\author{
Alex Mayhew, Danica Pawlick-Potts, kirstyn seanor, Arielle VanderSchans, (Grant \\ Campbell as moderator) \\ University of Western Ontario, London, ON, Canada
}

\title{
Emerging Diversity of Research in Library Studies (Panel)
}

\begin{abstract}
Résumé:
Research can take many forms, especially in a field as diverse as library studies. This panel will bring together several emerging scholars as they relate and compare their differing approaches to research. For some the subject area requires special considerations for research methods, for others the end goal brings into question what counts as research at all. It is our hope that this panel will illustrate the range of effort possible in our field and prove illuminating to our fellow scholars, both new and established.
\end{abstract}

\section{Discussion Topic}

Research is fundamental for the advancement of the field of Library and Information Science (LIS). As such, it is important to learn the scope of what research can be in the field. Research can take many forms - traditional interviews and coding, quantitative analyses, user studies of information management software or user interfaces, and even the design process itself. Our panel will facilitate a discussion between several emerging academics and their take on research. Each of the panel participants has a unique take on LIS research. While some lean towards traditional research conventions, others research unconventional subject matter, use novel research tools, or even resist the label of research all together.

These emerging scholars are entering the established LIS field and bringing with them new perspectives. This panel questions and explores what happens when individuals with eccentric viewpoints confront these traditional research methods and what happens when new voices face the established order? These emerging scholars navigate the waters of academia and can feel as if they are at times twisted to fit into a slot, and the questions they want to ask are shifted to what they are expected to ask. Our panelists must consider whether or not they go along with the establishment or resist, meanwhile the established academic community must integrate these new voices with familiar methods.

\section{Overview of the Panel Structure}

The panel will be moderated by Grant Campbell, an established LIS scholar. Following an introduction to the topic and to the participants, each participant will briefly (5-10 minutes) describe the research methods for their on-going work and some of the friction they have encountered. Following this overview, the second half of the allotted time will be spent in discussion. Due to the differing approaches to research and the differing assumptions about the 
role of research in scholarship, the discussion is expected to have elements of debate. There will also be an opportunity for questions from the audience.

\section{Relevant Qualifications and Contributions of Participating Panelists:}

Hailing from Western University's Faculty of Information and Media Studies, our panelists are $\mathrm{PhD}$ students in the Library and Information Science program. These students have a diverse background and unique research projects. They are all at different stages of their research, allowing them to provide different perspectives on the nature of research in LIS.

A brief description is provided for each panellist and the moderator.

Grant Campbell is the moderator for this panel. He has experience teaching a number of courses that explore the theory and practice of information organization and retrieval. In the graduate program in Library and Information Science, he currently teaches courses on the organization of information, the theory and practice of descriptive cataloguing, and classification and indexing. His research currently focuses on information resource description, with a special emphasis on the description, classification and access of electronic resources using traditional and non-traditional methods. Campbell bravely navigates this panel of $\mathrm{PhD}$ miscreants, acting a guides for their wayward thoughts on research in LIS.

Danica Pawlick-Potts, a first year PhD student, brings the perspective that it is important for information science to utilize knowledge from other disciplines to inform and enrich our own research. In particular, she believes that human information practice research should more carefully consider relevant philosophical discussions around concepts such as information and knowledge. In her own research, Danica draws on philosophical conceptions of trust to create a framework that is meaningful and useful in the context of human and artificial intelligence as a guide for her empirical inquiry. She also seeks to draw on cultural studies to consider how cultural conceptions and representations of artificial intelligence (AI) influence people's perceptions and how they relate to AI.

Arielle VanderSchans, a second year $\mathrm{PhD}$ candidate, brings an interdisciplinary approach to traditional LIS information-seeking research. In essence, her work seeks to navigate the relationship between creativity and serendipity for fiction writers; she calls this the magic of storytelling. As this is an area that has not had a lot of established research, Arielle's research methods are exploratory and focus on finding narratives through interviews. While her research methods are traditional, Arielle seeks to push against the ivory-tower voice and present her research in accessible language so that any reader can understand the magic behind storytelling. With her research she's presented with the opportunity to create her own tools of investigation, as a result her research methods are constantly evolving.

Alex Mayhew, a third year PhD candidate, is interested in thinking tools and philosophical engineering. He stubbornly insists on differentiating his project from what he thinks of as conventionally defined research. Alex conceives of a distinction between descriptive and 
prescriptive projects. Descriptive projects can be understood as curiosity driven efforts that alleviate some point of ignorance; he suggests most LIS research strives to be descriptive in this way. In contrast, the quintessential prescriptive project is one of design, the creation of some new system or tool that did not exist previously. In practice the interaction these two styles of engaging with the world can be a fruitful synthesis, a synthesis where arguably much of the work of academia is actually done; but, Alex invokes the artificial binary of descriptive and prescriptive efforts for a purpose. While this binary is a problematic model of reality (or academia), it serves to illustrate the different of types of projects that can be done, their utility, and which ones are encouraged or discouraged. His research is attempting to be not descriptive and not primarily synthetic but a prescriptive design of a new cataloguing system.

kirstyn seanor, a third year $\mathrm{PhD}$ candidate, is interested in virtual spaces as research sites. Through their dissertation work on the user tagging of pornography, they have had cause to confront what virtual artefacts - such as user tags and other metadata - convey about content, users, and the world at large. This has led them to consider user tags as documents, media, statements, and/or texts, each of which implies different approaches and readings. In addition to considering this a relatively novel and nuanced approach to user tags as a research object, they consider the matter to be particularly pressing as our world continues to be increasingly mediated through virtual spaces. 